\title{
A Population of Supramammillary Area Calretinin Neurons Terminating on Medial Septal Area Cholinergic and Lateral Septal Area Calbindin-Containing Cells Are Aspartate/Glutamatergic
}

\author{
Csaba Leranth ${ }^{1}$ and Jozsef Kiss ${ }^{2}$ \\ ${ }^{1}$ Department of Obstetrics and Gynecology and Section of Neurobiology, Yale University School of Medicine, New Haven, \\ Connecticut 06520-8063, and 2Joint Research Organization of the Hungarian Academy of Sciences and Semme/weis \\ Medical University, Neuroendocrine Unit, Budapest, Hungary
}

\begin{abstract}
The excitatory amino acid, aspartate/glutamate content of septal complex calretinin (CR)-, choline acetyltransferase plus substance $\mathrm{P}$-, and Leu-enkephalin (Leu-enk)-containing extrinsic afferents was examined. Experiments were carried out using the transmitter-specific $\left[{ }^{3} \mathrm{H}\right]$-D-aspartate retrograde tracer technique in combination with immunostaining for $\mathrm{CR}$, choline acetyltransferase, and Leu-enk. The extrinsic and intrinsic CR innervation of the same brain areas were elucidated on control rats and on animals in which the septum was surgically separated from its ventral afferents. Correlated light and electron microscopic double-immunostaining experiments were used to determine the synaptic connections between CR axon terminals and lateral septal area calbindin (CB)- and medial septal area choline acetyltransferase-immunoreactive neurons. Furthermore, to determine the synaptic power of supramammilloseptal aspartate/glutamatergic neurons on the septal complex, semiquantitative analyses were performed in the
\end{abstract}

supramammillary area on retrogradely (1) $\left[{ }^{3} \mathrm{H}\right]-\mathrm{D}$-aspartateradiolabeled and (2) HRP-labeled material.

The results demonstrated that a population of the extrinsic CR axons originating in the supramammillary area are aspartate/glutamatergic. These fibers forming asymmetric synaptic contacts terminate on both $\mathrm{CB}$ and cholinergic neurons. Intraseptal CR neurons, which establish symmetric synapses, innervate only lateral septal area neurons, including the CBcontaining cells. These observations, together with other published data, raise the possibility of a hippocampus-lateral septal (GABAergic CB-containing neurons)-supramammillary area (aspartate/glutamatergic cells)-medial septal (cholinergic neurons)-hippocampus signal loop, which might be involved in the generation and regulation of hippocampal theta rhythm activity.

Key words: autoradiography; Leu-enkephalin; substance $P$; acetylcholine; calbindin; double immunostaining; theta rhythm
It has been demonstrated that in the lateral septum (LS), in addition to the hippocamposeptal axon terminals, a large number of other boutons establish asymmetric synaptic contacts. They include extrinsic acetylcholine-, substance P (SP)-, and Leu-enkephalin (Leu-enk)-containing axon terminals (Szeidemann et al., 1995a,b). Furthermore, we have shown that the postsynaptic targets of these SP and Leu-enk fibers contain AMPA receptors (F. Varoqueaux and C. Leranth, 1996). These data, together with observations that ascribed a stimulatory role to SP and enkephalin in the LS (Nayar et al., 1987), i.e., parent neurons of these SP and enkephalin boutons do not contain GABA (Szeidemann et al., 1995a,b) and asymmetric synapses are assumed to represent stimulatory connections (Eccles, 1964), led us to the hypothesis that these fibers contain the excitatory transmitter aspartate/glutamate.

We also suggest that some of the supramammillary area calretinin (CR)-containing neurons projecting to the septal complex likewise contain aspartate/glutamate. This view is based on the

\footnotetext{
Received June 26, 1996; revised Sept. 12, 1996; accepted Sept. 19, 1996.

This study was supported by National Institutes of Health Grants NS 26068 and HD 23830 (C.L.) and O. T. K. A. Grants T-6372 and T-016977 (J.K.). We thank Dr. G. Buzsaki for reading this manuscript and for his helpful advice, M. Shanabrough for the excellent technical assistance, and Dr. J. H. Rogers for kindly providing the calretinin antiserum.

Correspondence should be addressed to Dr. Csaba Leranth, Yale University, School of Medicine, Department of Obstetrics and Gynecology, 339 Farnam Memorial Building, P.O. Box 208063, New Haven, CT 06520-8063.

Copyright (C) 1996 Society for Neuroscience $0270-6474 / 96 / 167699-12 \$ 05.00 / 0$
}

following. (1) Retrograde (Luiten et al., 1982; Saper, 1985; Vertes, 1988) and anterograde (Vertes, 1992) tracing experiments have demonstrated that neurons of the supramammillary area project to the septal complex; (2) our study (Kiss and Szeiffert, 1995) has shown that a large number of these projection cells contain the calcium-binding protein CR; (3) morphological data indicate that in the hippocampus, axon terminals of supramammillary CR cells form exclusively asymmetric synaptic contacts (Gulyas et al., 1992; Leranth and Nitsch; 1994; Magloczky et al., 1994; Nitsch and Leranth, 1996); (4) these cells are not GABAergic (Nitsch and Leranth, 1993, 1994); (5) rhythmically firing posterior hypothalamic neurons seem to be the primary driver of medial septal pacemaker neurons (Petsche et al., 1962; Kocsis and Vertes, 1994; Oddie et al., 1994), which are responsible for hippocampal theta activity (Jung and Kornmuller, 1938; Green and Arduini, 1954); and (6) it has been demonstrated that a population of supramammillary neurons are aspartate/glutamatergic (Carnes et al., 1990).

Numerous studies have demonstrated that $\left[{ }^{3} \mathrm{H}\right]$-D-aspartate is a transmitter-specific retrograde tracer, which is picked up selectively by aspartate/glutamatergic axons (Streit, 1980; Baughman and Gilbert, 1981; Rustioni and Cuenod, 1982; Oliver et al., 1983; Dememes et al., 1984; Matute and Streit,, 1985; Barbaresi et al., 1987; Christie et al., 1987; Fuller et al., 1987; Fuller and Price, 1988; Kisvarday et al., 1989; Carnes et al., 1990) and can be localized by autoradiography in their parent cells (Streit, 1980; Cuenod and Streit, 1983; Carnes et al., 1990). 
Table 1. Percentage of CR neurons among retrogradely $\left[{ }^{3} \mathrm{H}\right]-\mathrm{D}$ aspartate-radiolabeled cells $\left(\% \mathrm{CR}+\left[{ }^{3} \mathrm{H}\right]-\mathrm{D}\right.$ Asp) and $\left[{ }^{3} \mathrm{H}\right]-\mathrm{D}$ aspartate-labeled plus CR-immunoreactive neurons among the total number of CR-containing cells $\left(\%\left[{ }^{3} \mathrm{H}\right]-\mathrm{D}\right.$ Asp $\left.+\mathrm{CR} / \mathrm{CR}\right)$ in the supramammillary area of four rats

\begin{tabular}{llll}
$\begin{array}{l}\text { Rat } \\
\text { no. }\end{array}$ & $\begin{array}{l}\left(\% \mathrm{CR}+\left[{ }^{3} \mathrm{H}\right]-\mathrm{D}\right. \\
\left.\mathrm{Asp} /\left[{ }^{3} \mathrm{H}\right]-\mathrm{D} \text { Asp }\right)\end{array}$ & $\begin{array}{l}\%\left[{ }^{3} \mathrm{H}\right]-\mathrm{D} \text { Asp } \\
+\mathrm{CR} / \mathrm{CR}\end{array}$ & $\begin{array}{l}\text { No. of } \\
\text { sections }\end{array}$ \\
\hline 1 & $89.9 \pm 0.4$ & $16.45 \pm 0.8$ & 6 \\
2 & $88.3 \pm 1.0$ & $17.67 \pm 0.7$ & 8 \\
3 & $86.5 \pm 0.9$ & $17.26 \pm 0.9$ & 8 \\
4 & $91.3 \pm 0.6$ & $18.15 \pm 0.5$ & 8 \\
\hline
\end{tabular}

Therefore, to assess the validity of the aforementioned hypotheses, immunostaining for choline acetyltransferase (ChAT), Leuenk, and CR was combined with autoradiographic detection of retrogradely transported $\left[{ }^{3} \mathrm{H}\right]$-D-aspartate. Furthermore, double immunostaining for $\mathrm{CR}$ plus ChAT and CR plus calbindin (CB) was performed. In addition, an analysis was performed on the CR innervation of the septum of intact and surgically manipulated rats.

\section{MATERIALS AND METHODS}

Animals. Twenty adult Sprague Dawley (300-320 gm) male and female rats were used in this study. Twelve animals were devoted to the autoradiographic experiments, and eight were used for the single- and doubleimmunostaining experiments. Animals were kept under standard laboratory conditions, with tap water and regular rat chow ad libitum, in a $12 \mathrm{hr}$ light/dark cycle.

$\left[{ }^{3} \mathrm{H}\right]$-D-aspartate injection. Two days before the rats were killed, $\left[{ }^{3} \mathrm{H}\right]-$ D-aspartate $(10-20 \mu \mathrm{Ci}$ in $0.1-0.2 \mu \mathrm{l}$ of saline) was injected unilaterally into different areas of the LS [lateral (L), $0.4-0.8 \mathrm{~mm}$; ventral (V), 5.4-6.0 mm; anterior-posterior (AP), 1.2-0.4 mm]. Before the injections, an aliquot of $\left[{ }^{3} \mathrm{H}\right]$-D-aspartic acid (Amersham, Arlington Heights, IL) was neutralized by the addition of $\mathrm{NaOH}$. Then it was evaporated to dryness in a vacuum chamber and rediluted in saline to a final concentration of $100 \mu \mathrm{Ci}$ in $1.0 \mu \mathrm{l}$. The injection was made for $10 \mathrm{~min}$ via a glass capillary (20 $\mu \mathrm{m}$ outer diameter) connected to a motorized microsyringe. After the injection, the capillary was left in place for an additional $10 \mathrm{~min}$.

Tissue preparation. Animals were killed under ether anesthesia by transcardial perfusion of $50 \mathrm{ml}$ heparinized saline, followed by a fixative containing either $2 \%$ glutaraldehyde, $4 \%$ paraformaldehyde and $0.2 \%$ picric acid in $0.1 \mathrm{~m}$ phosphate buffer (PB), $\mathrm{pH} 7.35$, for the autoradiographic experiments, or $0.1 \%$ glutaraldehyde, $4 \%$ paraformaldehyde and $20 \%$ picric acid in PB for the single- and double-immunostaining studies. Tissue blocks were dissected out and post-fixed for $2 \mathrm{hr}$ in the same but glutaraldehyde-free fixative. Then they were rinsed in several changes of ice-cold $\mathrm{PB}$, and $60 \mu \mathrm{m}$ vibratome (Lancer) sections containing the septum, perifornical, supramammillary, and laterodorsal tegmental (LDTG) areas and the hippocampus were cut. Subsequently, the sections were treated with $1 \%$ sodium borohydride in PB for 10-30 min to eliminate unbound aldehydes from the tissue (Kosaka et al., 1986).

Immunostaining and autoradiography. Light microscopic immunostaining was performed for ChAT, Leu-enk, and CR on vibratome sections of the LDTG, perifornical area, and supramammillary nucleus, respectively. In addition, ipsilateral hippocampal sections were immunostained for $\mathrm{CR}$ as a control. All of the incubations were carried out at room temperature, and sections were rinsed thoroughly $(3 \times 15 \mathrm{~min})$ in PB between each incubation step. The primary antisera and their dilutions were as follows: rat anti-ChAT (Boehringer Mannheim, Indianapolis, IN) 1:50; rabbit anti-Leu-enk (Zamir et al., 1984), a generous gift of Dr. Gorcs, 1:15,000;

$\begin{aligned} & \text { Table 2. Percentage of retrogradely WGA-HRP-labeled CR-containing } \\
& \text { neurons among the total number of supramammillary area CR- } \\
& \text { immunoreactive cells } \text { (\% WGA-HRP + CR/CR) of two rats }\end{aligned}$
\begin{tabular}{lcc} 
Rat no. & $\%$ WGA-HRP + CR/CR & No. of sections \\
\hline 1 & $48.65 \pm 1.2$ & 8 \\
2 & $50.23 \pm 0.9$ & 8 \\
\hline
\end{tabular}

and rabbit anti-CR (Rogers, 1987), 1:20,000. Antisera were diluted in PB containing $0.3 \%$ Triton $\mathrm{X}-100$ and $0.1 \%$ sodium azide. Sections were incubated in primary antibody for $12 \mathrm{hr}$. This was followed by incubation of the sections in the corresponding biotinylated secondary antiserum (rabbit anti-rat or goat anti-rabbit IgG, 1:250 in PB; Vector Labs, Burlingame, $\mathrm{CA}$ ) and then in ABC Elite (1:250 in PB; Vector Labs), each for $2 \mathrm{hr}$. The tissue-bound peroxidase was visualized by a diaminobenzidine (DAB) reaction ( $15 \mathrm{mg}$ DAB, $165 \mu \mathrm{l} 0.3 \% \mathrm{H}_{2} \mathrm{O}_{2}$ in $30 \mathrm{ml} \mathrm{PB}$ for $5-10$ min). After final rinses in $\mathrm{PB}$, sections were mounted on gelatin-coated slides and air-dried. Slides were than dipped in a nuclear emulsion (Ilford $\mathrm{L} 4$, diluted to $1: 1$ in double-distilled water at $40^{\circ} \mathrm{C}$ ) and stored in the dark for 4-8 weeks. The sections were developed in D19 (Eastman Kodak, Rochester, NY) at $15^{\circ} \mathrm{C}$. After photo-fixing and washing in deionized water, sections were dehydrated and coverslipped with Permount and examined under the light microscope.

Septal undercut and immunostaining for $C R$. Two of the rats were fixed in a stereotaxic apparatus, and all of the septal afferents coming from a ventral direction were unilaterally transected with an L-shaped knife. The details of this operation have been described previously (Szeidemann et al., 1995a,b). After a 5 d survival period, rats were killed (see above; the fixative contained $4 \%$ paraformaldehyde, $0.2 \%$ glutaraldehyde and $20 \%$ picric acid in $\mathrm{PB}$ ), and septal vibratome sections were immunostained for $\mathrm{CR}$ as described above, except that the tissue-bound peroxidase was visualized by an Ni-DAB reaction (see below). Sections for electron microscopy were freeze/thaw-treated in liquid nitrogen (sections were placed in a vial containing $10 \%$ sucrose in PB; the vial was frozen rapidly in liquid nitrogen and then allowed to thaw to room temperature) before the application of primary antiserum. In addition, no Triton X-100 was used, and sections were incubated for $48 \mathrm{hr}$ at $4^{\circ} \mathrm{C}$. A brown DAB reaction was used to visualize tissue-bound peroxidase. Finally, the sections were osmicated and embedded (see below).

Double immunostaining for $C R$ and $C h A T$ and $C R$ and $C B$. To examine the relationship between medial septal/diagonal band cholinergic (ChATimmunoreactive) neurons and CR axon terminals, as well as CR boutons and lateral septal area CB-containing neurons, correlated light and electron microscopic double-immunostaining experiments were performed using our modification (Leranth and Nitsch, 1994; Szeidemann et al., 1995a,b) of the Ni-intensified DAB/DAB double-immunostaining technique. Briefly, sections were first immunostained for $\mathrm{CR}$ as described above; however, the tissue-bound peroxidase was visualized with a darkblue to black Ni-intensified DAB reaction [ $15 \mathrm{mg} \mathrm{DAB}, 12 \mathrm{mg} \mathrm{NH}_{4} \mathrm{Cl}$, $0.12 \mathrm{mg}$ glucose oxidase, $600 \mu \mathrm{l} 0.5 \mathrm{M} \mathrm{Ni}\left(\mathrm{NH}_{4}\right)_{2} \mathrm{SO}_{4}$, and $600 \mu \mathrm{l} 10 \%$ $\beta$-D-glucose in $40 \mathrm{ml} \mathrm{PB}$, for $4-8 \mathrm{~min}]$. After several washes in PB, sections were immunostained further for ChAT (see above; dilution was $1: 10$ ) or for $\mathrm{CB}$. In the latter, sections were incubated in a monoclonal $\mathrm{CB}$ antiserum (Sigma, St. Louis, MO) diluted 1:5000 in PB containing 0.3\% Triton X-100 and $0.1 \%$ sodium azide. After a $3 \times 15$ min wash in PB, sections were incubated in the appropriate secondary antiserum (rabbit anti-rat or rabbit anti-mouse IgG, 1:50 in PB; Organon Teknika, Durham, $\mathrm{NC})$ and then in either rat-PAP or rabbit-PAP (1:100 in PB; Organon Teknika), each for $2 \mathrm{hr}$ at room temperature. After the final brown DAB reaction (15 mg DAB, $165 \mu \mathrm{l} 0.3 \% \mathrm{H}_{2} \mathrm{O}_{2}$ in $30 \mathrm{ml} \mathrm{PB}$ for 5-10 min) and several rinses in $\mathrm{PB}$, sections for light microscopy were mounted on gelatin-coated slides, dehydrated, and mounted in Permount. Sections for electron microscopy were processed in the same way as for light microscopy except that they received a freeze/thaw treatment, no Triton X-100 was used, and the incubations in the primary antisera were carried out for $48 \mathrm{hr}$ at $4^{\circ} \mathrm{C}$. Then they were wet-mounted on slides and colorphotographed. After this, sections were osmicated $\left(1 \% \mathrm{OsO}_{4}\right.$ in $\mathrm{PB}$ for 1 hr), dehydrated in graded ethanol (the $70 \%$ ethanol contained $1 \%$ uranyl acetate, for $30 \mathrm{~min}$ ), and embedded in Durcupan (Fluka, Swiss). Ribbons of ultrathin sections of the previously photographed putative synaptic contacts were collected on Formvar-coated single-slot grids and examined in a Philips CM-10 electron microscope.

Retrograde labeling of supramammillary $C R$ neurons. In two animals, large $(0.8 \mu \mathrm{l})$ wheat germ agglutinin-conjugated HRP (WGA-HRP; $2.5 \%$ diluted in saline) injections were placed via a glass micropipette (40-50 $\mu \mathrm{m}$ outer diameter) connected to a microsyringe into the same septal areas $(\mathrm{L}, 0.4-0.8 \mathrm{~mm} ; \mathrm{V}, 5.4-6.0 \mathrm{~mm}$; AP, $1.2-0.4 \mathrm{~mm})$ where, in other rats, the $\left[{ }^{3} \mathrm{H}\right]$-D-aspartate was injected. After a $36 \mathrm{hr}$ survival period, animals were killed under ether anesthesia by transcardial perfusion of 50 $\mathrm{ml}$ saline followed by a fixative containing $1.5 \%$ glutaraldehyde and $1.5 \%$ paraformaldehyde in PB. Vibratome sections cut throughout the brain were rinsed $(3 \times 15 \mathrm{~min})$ in $\mathrm{PB}$ and incubated for $20 \mathrm{~min}$ in $1 \%$ sodium borohydride, and the WGA-HRP was visualized by a glucose oxidase 
reaction $(15 \mathrm{mg} \mathrm{DAB}, 12 \mathrm{mg}$ ammonium chloride, $0.12 \mathrm{mg}$ glucose oxidase, and $60 \mathrm{mg} \beta$-D-glucose in $30 \mathrm{ml} \mathrm{PB}$ for $30-45 \mathrm{~min}$ ). Thereafter sections were immunostained for $\mathrm{CR}$ for light microscopic examination (see above).

Control experiments. Although the primary antisera used in these experiments are widely used and well characterized, control experiments were performed. Sections were processed through the entire immunohistochemical sequence, except that the primary antisera (for the doubleimmunostaining experiments, only one of the primary or secondary antisera) were omitted or replaced by corresponding preimmune serum. Under these conditions, no immunostaining or only single immunostaining could be observed.

Semiquantitative analysis. Counts were made on each vibratome section prepared from the supramammillary area (five to eight sections per animal) of retrogradely radiolabeled plus CR immunostained (four rats) and retrogradely WGA-HRP-labeled plus CR immunostained (two animals) material. The total number of neurons that were retrogradely labeled (WGA-HRP or $\left[{ }^{3} \mathrm{H}\right]$-D-aspartate) and CR-containing and CRimmunoreactive only was determined, and their ratios were calculated.

\section{RESULTS}

\section{Injection sites}

Similar to the observation of others (Carnes et al., 1990), in the septal complex of the $\left[{ }^{3} \mathrm{H}\right]$-D-aspartate-injected rats, there was a small focus of labeling at the end of the $\left[{ }^{3} \mathrm{H}\right]$-D-aspartate needle injection track, characterized by some neuronal loss and gliosis. Around this site, a relatively large, concentric area could be observed that was marked by a dense silver-grain labeling. Because of the concentration of silver grains, individual cell labeling could not be recognized. Even after injections placed in the most lateral part of the LS, the zone of the injection spread (0.6-1.0 $\mathrm{mm}$ ) occupied areas of the medial septum.

Because of the large volume $(0.8 \mu \mathrm{l})$ of the WGA-HRP injections, both lateral and medial septal areas were heavily labeled on the ipsilateral side. In one rat, the WGA-HRP deposit also could be observed in the contralateral medial septal area.

\section{Distribution and neurochemistry of radiolabeled and WGA-HRP-labeled neurons}

A large number of retrogradely [ $\left.{ }^{3} \mathrm{H}\right]$-D-aspartate-labeled, supposedly aspartate/glutamate-containing neurons could be observed in the supramammillary area and ipsilateral hippocampus, with fewer radiolabeled neurons in the contralateral hippocampus and central medial preoptic nucleus. The description of the preoptic area aspartate/glutamate-containing cells is the subject of another study. All of the hippocampal cells that contained retrogradely transported $\left[{ }^{3} \mathrm{H}\right]$-D-aspartate seemed to be pyramidal cells, and none showed immunoreactivity for CR.

In this material, three major types of neurons could be observed in the supramammillary area: (1) neurons containing only CR (these cells represented the majority of supramammillary area neurons); (2) a few cells that were only retrogradely labeled with $\left[{ }^{3} \mathrm{H}\right]$-D-aspartate; and (3) double-labeled neurons containing both aspartate/glutamate and CR (Fig. 1a-c; Table 1). The majority of the last two groups of cells could be observed in the lateral part (ipsilateral to the injection) of the supramammillary area. Only a few of these neurons were seen near the midline, and only one or two cells per animal were seen in the contralateral side.

Numerous ChAT- and Leu-enk-immunoreactive neurons were seen on sections from the LDTG and perifornical areas, respectively; however, neither the ChAT- nor the Leu-enk-immunoreactive cells contained retrogradely transported $\left[{ }^{3} \mathrm{H}\right]$-D-aspartate.

Retrogradely WGA-HRP-labeled neurons were found in many brain areas known to project to the septal complex (for review, see Jakab and Leranth, 1995); however, CR-immunoreactive plus
WGA-HRP-containing cells were observed solely in the supramammillary area. The distribution pattern of these cells was similar to those of radiolabeled CR neurons. Obviously, because of penetration problems (caused by the high concentration of glutaraldehyde in the fixative) of the immunoreagents, CRimmunoreactive, retrogradely WGA-HRP-labeled cells were seen only on the surface of the vibratome sections. It must be noted, however, that even with this limitation, these double-labeled cells could be detected in much deeper layers of the vibratome sections than the radiolabeled CR neurons.

\section{Semiquantitative analysis}

The number of retrogradely radiolabeled cells in the supramammillary area, depending on the orocaudal location of the sections taken from four rats, varied between 75 and 120 . On every section, however, as well as in different animals (in spite of the fact that the location of the injections was different), the percentage of radiolabeled CR-containing neurons was constant, being between $88.3 \% \pm 1.0$ and $91.3 \% \pm 0.6$. Furthermore, among the CRimmunoreactive supramammillary neurons (350-400 per section), in a homogeneous distribution in the orocaudal direction, approximately $17 \%$ of the CR cells were radiolabeled (Table 1). These data indicate that in the orocaudal direction, the supramammilloseptal aspartate/glutamate-containing, projective CR cells are distributed homogeneously in the lateral part of the supramammillary area.

In one animal, because of the spread of the WGA-HRP deposit into the contralateral medial septal area, retrogradely labeled neurons were also seen in the contralateral supramammillary area; however, the calculation was performed on the ipsilateral site only. In both animals, the percentage of the retrogradely WGA-HRP-labeled plus CR-immunoreactive cells among the total number of CR-containing neurons (Table 2) was consistently much higher $(49 \%)$ than those of retrogradely radiolabeled CRimmunoreactive neurons (Table 1).

\section{Extrinsic and intrinsic CR innervation of the septal complex}

A detailed morphological and neurochemical analysis of the CR innervation of the septal complex was beyond the focus of this study. Briefly, under the light microscope, the overwhelming majority of CR neurons was observed in an upside-down V-shaped area at the border between the lateral and medial septum. In addition, scattered cells were seen in the dorsal and ventral parts of the LS, as well as in the medial septum diagonal band of Broca. Most CR-immunoreactive fibers and boutons were observed in the intermediate and ventral parts of the LS and occupied a zone lateral to the aforementioned V-shaped area of CR neurons. Furthermore, numerous CR fibers running in a vertical direction and CR boutons were seen in the medial septum (Fig. 2a,c). In the LS, the majority of CR axon terminals were closely associated with the soma of nonimmunoreactive neurons (Fig. $2 b$ ). In the medial septum, these basket-like structures were seldom seen. Five days after a unilateral septal undercut, CR axons on the ipsilateral medial septal area disappeared completely (Fig. 2c), and in the ipsilateral LS, their density was greatly reduced (Fig. 2d,e).

In the electron microscope, two types of CR boutons could be detected in the LS. One type formed symmetric synapses, whereas the other, which comprised the majority of all of the boutons, established asymmetric synaptic membrane specializations. In the medial septum, only asymmetric contacts were seen. After the 

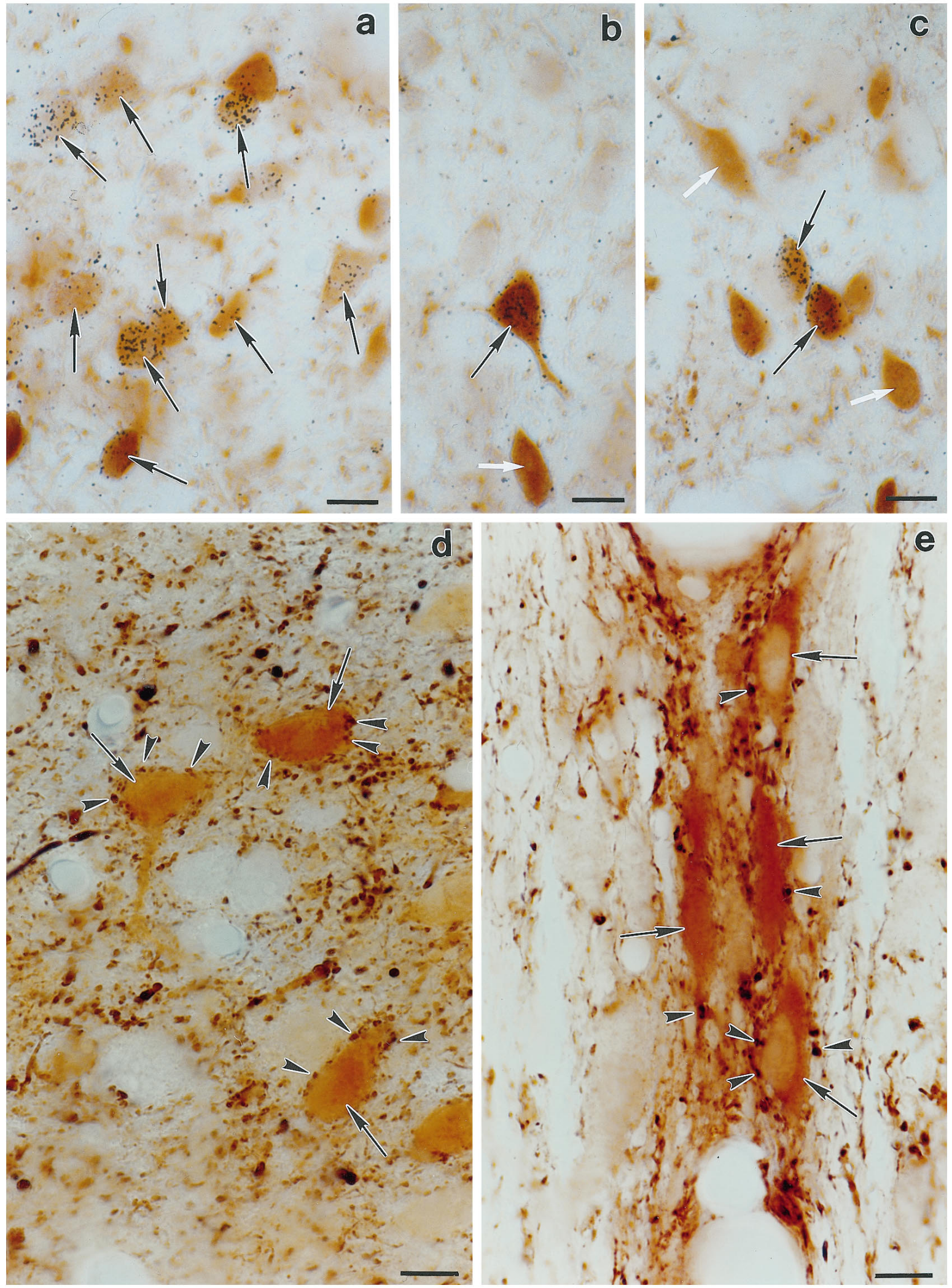

Figure 1. Color light micrographs demonstrate radiolabeled neurons in the supramammillary area immunostained for $\mathrm{CR}$ after a $\mathrm{D}-\left[{ }^{3} \mathrm{H}\right]$-aspartate injection into the septum $(a-c)$, and the results of double-immunostaining experiments for CR plus CB $(d)$ and CR plus ChAT (e). Black arrows on $a-c$ point to radiolabeled, CR-immunoreactive neurons. White arrows on $b$ and $c$ label CR-containing cells that are not retrogradely radiolabeled. On $d$ and $e$, immunoreactivity for $\mathrm{CR}$ was labeled with the dark-blue to black $\mathrm{Ni} / \mathrm{DAB}$ reaction; $\mathrm{CB}$ - and ChAT-containing profiles were labeled with the brown $\mathrm{DAB}$ reaction. $d$ shows CB neurons (arrows) surrounded by numerous CR-immunoreactive puncta (some are labeled by arrowheads) in the intermediate part of the lateral septal nucleus; $e$ demonstrates a group of ChAT-immunoreactive neurons (arrows) in the dorsal part of the medial septum. These cells are contacted by a few CR-containing profiles (arrowheads). Scale bars, $10 \mu \mathrm{m}$. 


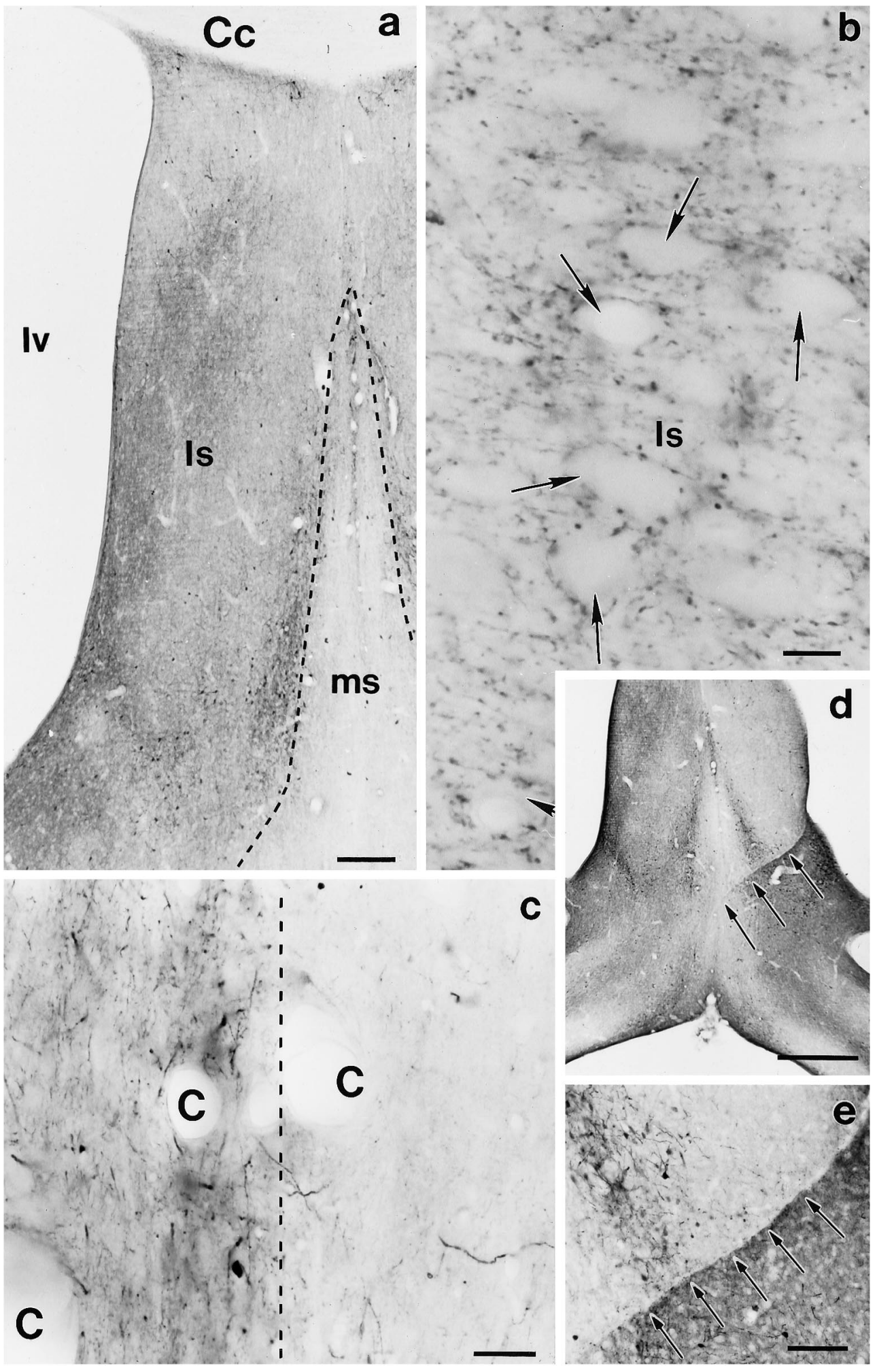

Figure 2. Light micrographs of CRimmunostained septal complex of control $(a, b)$ and septal undercut rats $(c-e)$. The majority of CR-containing neurons are accumulated in an upside-down $\mathrm{V}$-shaped area at the border between the medial $(\mathrm{ms})$ and lateral septum $(l s)$. In addition, few CR-immunoreactive neurons are seen distributed homogeneously in both lateral and medial septal areas $(a, d)$. A dense network of CRimmunoreactive axons are seen in the intermediate and ventral zone of the LS and lateral to the V-shaped area. In this area, most of the boutons seem to be associated with immunonegative somata (b). In the medial septum, the CR fiber network is much less dense, and most of the CR axons run in a vertical direction $(c$, left $)$. Five days after a unilateral septal undercut (arrows in $d$ and $e$ ), on the ipsilateral side the density of CR axons greatly decreased in both lateral $(d)$ and medial septal areas $(c, r i g h t)$. On $e$, note the near-complete absence of CR axons above the cut (arrows). The dashed line on $c$ indicates the midline. Large capillaries $(C)$ are characteristic in the medial septal area. Scale bars: $a, 200 \mu \mathrm{m} ; b, 10$ $\mu \mathrm{m} ; d, 500 \mu \mathrm{m} ; e, 100 \mu \mathrm{m}$. septal undercut, only symmetric synaptic contacts of CR boutons were found in the ipsilateral LS.

\section{Double immunostaining for CR plus ChAT and CR} plus $\mathrm{CB}$

These experiments resulted in a dark-blue to black labeling of CRimmunoreactive profiles and brown $\mathrm{DAB}$ labeling of $\mathrm{CB}-$ and ChAT-containing neurons in the lateral and medial septal areas, respectively (Fig. 1d,e). Under the light microscope, it appeared that CR-immunoreactive axon terminals form basket-like structures around both CB-containing (Figs. $1 d, 3 a$ ) and a population of ChATcontaining (Figs. 1e, $4 a, 5 a$ ) neurons. The majority of CR-innervated $\mathrm{CB}$ neurons were found distributed homogeneously in the lateral area of the intermediate and ventral parts of the LS. CR-contacted ChAT cells were seen exclusively in the upper dorsal part of the 
medial septum (Figs. 1e, $4 a, 5 a$ ). These neurons were not seen in the vertical and horizontal limbs of the diagonal band.

Electron microscopic analysis revealed that a large population of CR boutons terminating on lateral septal area CBcontaining neurons establish asymmetric synaptic contacts (Fig. $3 b-e$ ); however, symmetric synapses were also observed (not shown). In the medial septum, only a few ChAT-containing somata were contacted by CR-immunoreactive boutons (Fig. 4). Although under the light microscope CR boutons appeared to contact the soma of ChAT cells (Figs. 1e, 4a, 5a), only a fraction formed axosomatic synapses (Fig. $4 b-f$ ); the majority of CR axon terminals formed synapses with ChATimmunoreactive dendritic shafts (Fig. $5 b-d$ ) and immunonegative dendrites (Fig. 4e). It is important to note that in the medial septum, all of the CR boutons formed exclusively asymmetric synaptic membrane specializations (Figs. $4 b-f, 5 b-d$ ).

\section{DISCUSSION}

\section{Technical considerations}

A large number of well characterized aspartate/glutamate antisera are available and have been used. Because aspartate/glutamate is present in low concentrations in nonaspartate/glutamatergic neurons, however, the recognition of these neurons is ambiguous. Therefore, we selected the more labor-intensive radiolabeling method, because there is evidence which indicates that retrogradely transported $\left[{ }^{3} \mathrm{H}\right]$-D-aspartate selectively labels neurons that use aspartate/glutamate as their transmitter (for review, see Carnes et al., 1990). The present observations also support this notion, because after $\left[{ }^{3} \mathrm{H}\right]$-D-aspartate injection into the septum, only the known aspartate/glutamate-containing hippocampal principal neurons (Storm-Mathisen et al., 1983), but none of the GABAergic hippocamposeptal nonprincipal cells (Alonso and Kohler, 1982; Shinoda et al., 1987; Toth and Freund, 1992), were retrogradely radiolabeled.

The percentage of aspartate/glutamatergic CR-containing supramammilloseptal cells should be much higher than the results (Table 1) of the $\left[{ }^{3} \mathrm{H}\right]$-D-aspartate experiments would indicate because (1) the retrogradely transported WGA-HRP can be visualized throughout the entire depth of the sections (although the penetration of immunoreagents for CR immunostaining was limited by the high concentration of glutaraldehyde in the fixative), whereas the radiolabeling for aspartate/glutamate is confined to the very surface; and (2) WGA-HRP labels trespassing supramammillohippocampal neurons, whereas aspartate/glutamate is thought to be picked up only by axon terminals (for review, see Carnes et al., 1990).

\section{CR innervation of the septal complex}

The description of the CR innervation of the septal complex was necessary, because previous studies showed only that supramammillary CR neurons project to the septum (Kiss and Szeiffert, 1995); however, their mode of termination and, most importantly, the neurochemical content of their postsynaptic partners has not yet been elucidated.

The results indicate that the extrinsic CR system establishes asymmetric contacts and innervates both the medial and lateral septal areas, whereas the intrinsic CR system forms exclusively symmetric synapses in the LS. This view is supported by the following facts. (1) Only asymmetric CR synapses were found in the medial septum, and (2) after a septal undercut, although asymmetric CR synapses disappeared from both the medial and LS, the symmetric CR synapses were still present in the LS. The lack of CR axons in the ipsilateral medial septum after the septal undercut indicates that intrinsic septal CR neurons, even though some were found inside the boundaries of the medial septum diagonal band of Broca, do not terminate in this area but only in the LS, and/or they project to other brain areas, including the supramammillary nucleus. This is supported by the observation that septal CR neurons can be retrogradely labeled from the supramammillary area (Kiss and Szeiffert, 1995), and after a unilateral septal undercut, only very few CR boutons remained in the LS.

The extrinsic CR system originates in the supramammillary area, because after a retrograde tracer injection into the septal complex, retrogradely labeled CR neurons were seen solely in the ipsilateral supramammillary nucleus (Kiss and Szeiffert, 1995). There are indications that at least a population of these supramammilloseptal projective cells also project to the hippocampus, because after injection of two contrasting retrograde tracers into the hippocampus and septum, some of the supramammillary neurons were labeled with both retrograde tracers (Kiss and Szeiffert, 1995).

The majority of the medial septum diagonal band of Broca ChAT neurons are contacted by CR boutons on their dendrites, and only a few, located mostly in the medial septum, receive axosomatic CR synapses (Figs. 4, 5). Therefore, one can speculate that the latter septohippocampal cholinergic cells have a more profound effect on the hippocampus. On the other hand, CB neurons are surrounded by $\mathrm{CR}$-immunoreactive baskets. The other difference between the innervation of $\mathrm{CB}$ and cholinergic neurons is that ChAT cells are targeted only by extrinsic CR systems, whereas $\mathrm{CB}$ neurons receive input from both extrinsic and intrinsic CR systems.

\section{A population of supramammilloseptal CR neurons are aspartate/glutamatergic}

The major observation of this study is that a population of the supramammilloseptal CR neurons contain aspartate/glutamate. Furthermore, both LDTG area SP- and perifornical area Leuenk-immunoreactive cells do not contain this excitatory transmitter.

Although it seems that practically all of the supramammilloseptal aspartate/glutamatergic neurons contain CR (Table 1), the result of the WGA-HRP retrograde tracer study demonstrated that the supramammilloseptal CR pathway may also contain a large population of nonaspartate/glutamatergic CR fibers (Table 2). The transmitter content of the parent neurons of these latter axons is not yet known. Because of their calciumbinding protein content, however, they may be capable of fast firing (Rogers, 1987).

\section{Functional considerations}

The septum and its reciprocal connection with the hippocampal complex play an important role in hippocampal theta rhythm activity. It has been shown that (1) a large population of medial septal neurons discharge rhythmically and are phase-locked to the hippocampal theta waves (Petsche et al., 1962; Gogolak et al., 1968; Apostol and Creutzfeld, 1974; Vinogradova et al., 1980; Gaztelu and Buno, 1982; Lamour et al., 1984; Alonso et al., 1987); (2) the immobility-related hippocampal theta activity is associated with septohippocampal, cholinergic neurons (Bland, 1986); and (3) the hippocampal feedback via the LS is necessary for the maintenance of hippocampal theta rhythm (DeFrance et al., 1971, 1976; McLennan and Miller, 1974; Twery et al., 1990). 


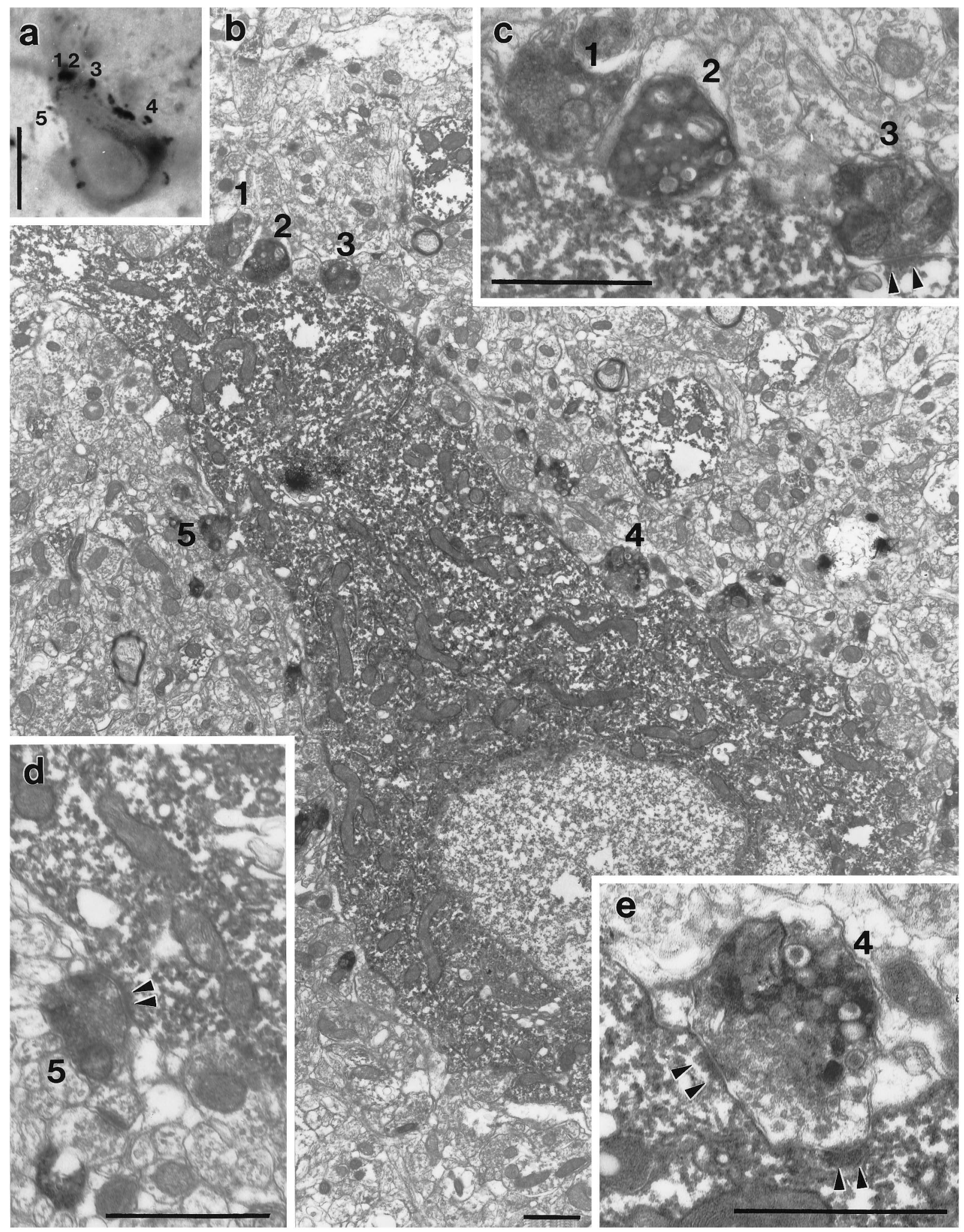

Figure 3. Light $(a)$ and electron micrographs $(b-e)$ demonstrate the result of a correlated double immunostaining for CR and CB in the LS. The CB neuron $(a)$ and its putative axosomatic synaptic contacts with CR-containing axon terminals (1-5) were serially sectioned and analyzed in the electron microscope. Note that boutons 3-5 form asymmetric synaptic contacts (arrowheads). $c-e$ are high-power magnifications of boutons 1-3, 5, and 4, respectively. Scale bars: $a, 10 \mu \mathrm{m} ; b-e, 1 \mu \mathrm{m}$. 


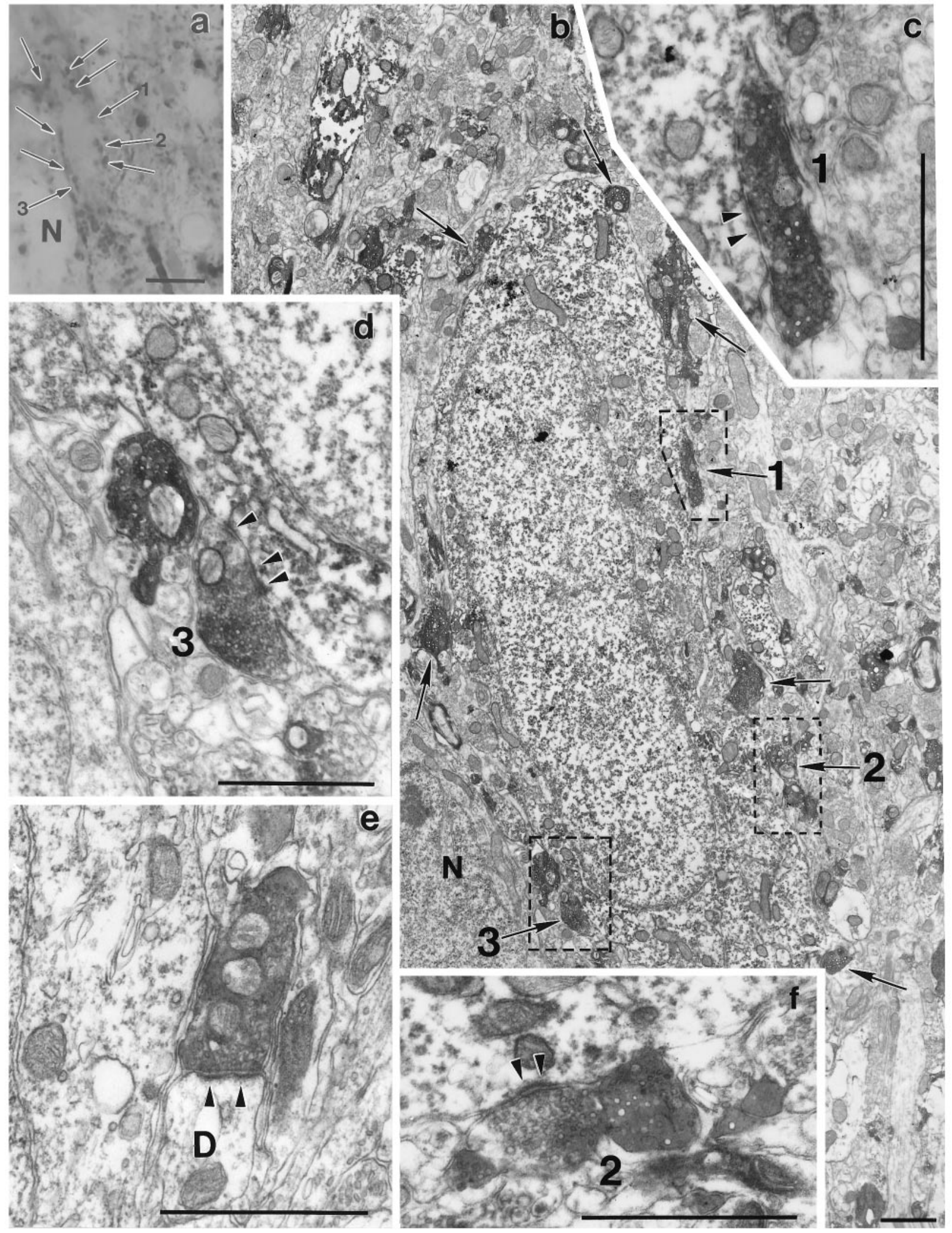

Figure 4. Light $(4 a, 5 a)$ and electron micrographs show the medial septum double-immunostained for CR and ChAT. Figure 4 demonstrates one of the very few ChAT-immunoreactive neurons that established axosomatic synaptic contacts with CR boutons. The putative synaptic contacts of CR boutons (arrows on $4 a$ and $5 a$ ) were further analyzed in the electron microscope. CR axon terminals 1-3 were found to form asymmetric synaptic contacts with the soma of the ChAT neuron. $c, d$, and $f$ are high-power magnifications of the boxed areas on $b$. $f$ shows bouton 2 (Figure legend continues). 

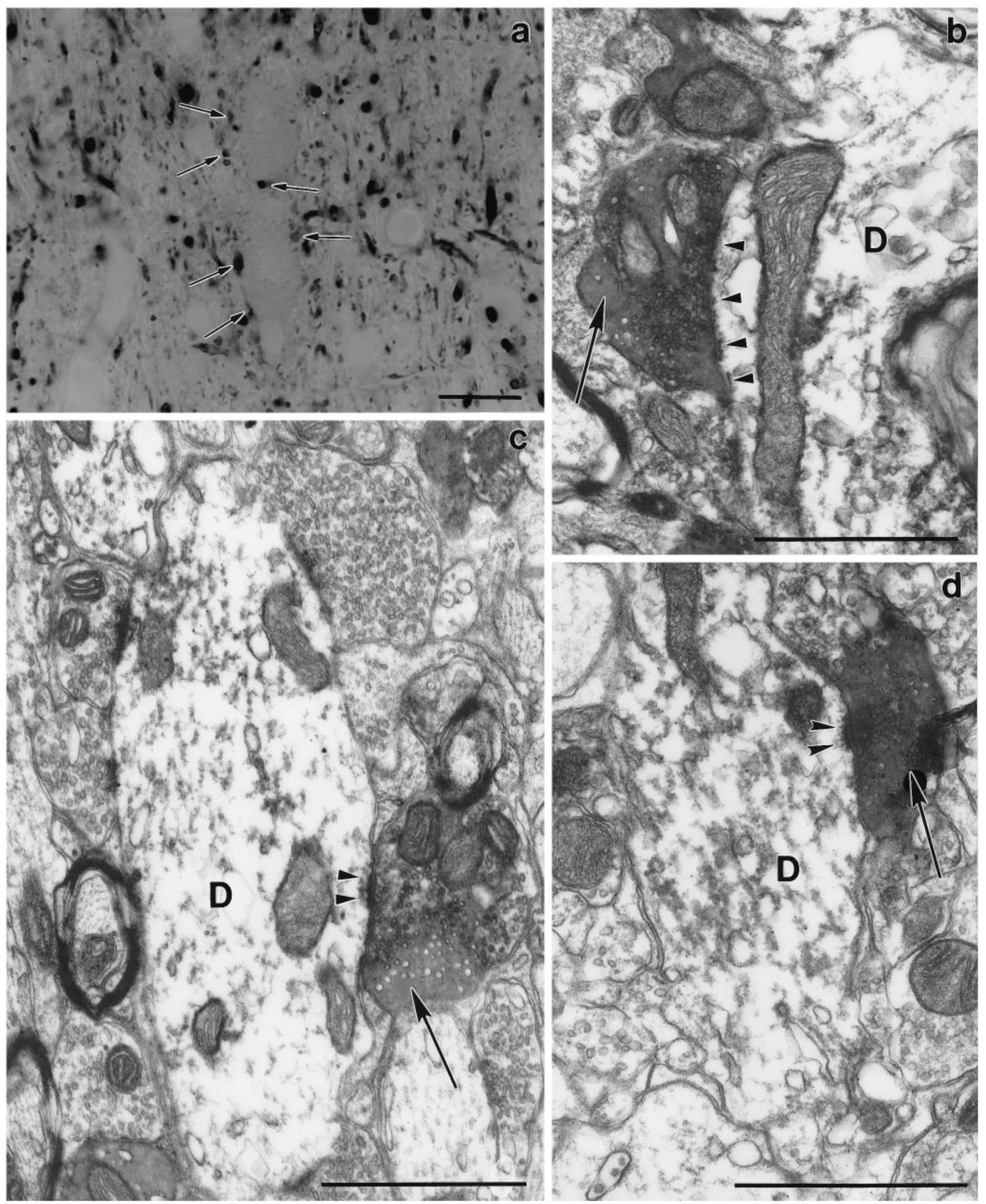

Figure 5. For details, refer to Figure 4 legend.

(turned $90^{\circ}$ and taken from another section); $e$ demonstrates a CR bouton forming an asymmetric synaptic contact with an unlabeled dendrite $(D)$. Fig. $5 a$ shows two ChAT-immunoreactive medial septal neurons. In the electron microscope, the dark-blue to black (on the original color photographs) CR axons (arrows) surrounding these cells were not found to form synaptic contacts. $b-d$ demonstrate asymmetric axodendritic synaptic contacts (arrowheads) between CR-containing boutons (arrows) and ChAT-immunoreactive dendrites $(D)$. The CR-immunoreactive boutons that are entirely $(b)$ or partially $(c$, $d$ ) filled with the homogeneous, metallic deposit of the Ni-DAB reaction can be distinguished easily from the ChAT-containing profiles labeled with the fine precipitate of the DAB reaction. Scale bars: $4 a, 5 a, 10 \mu \mathrm{m} ; 4 b-d, 5 b-d, 1 \mu \mathrm{m}$. 
In line with these observations are previous studies, including our own (Leranth and Frotscher, 1989), which assumed that the septohippocamposeptal loop is completed by a GABAergic lateral septal projection to the medial septum (McLennan and Miller, 1974, 1976; Swanson and Cowan, 1979; Kohler and ChanPalay, 1983; Panula et al., 1984; Onteniente et al., 1986). Recent studies, however, demonstrated that the LS-medial septum pathway is nonexistent or extremely sparse (Staiger and Nurnberger, 1991; Leranth et al., 1992; Witter et al., 1992). Furthermore, supramammillary area neurons play a pivotal role in hippocampal theta rhythm (for review, see Kocsis and Vertes, 1994). This is supported by observations that procaine injections into the medial septum that abolished theta activity in the hippocampus did not alter the rhythmical firing of supramammillary neurons (Kirk and McNaughton, 1991), and hippocampal theta activity could be reversibly blocked by procaine injections into the supramammillary area (Oddie et al., 1994).

It is well established that lateral septal neurons are innervated by hippocampal fibers and that these cells, including the CBcontaining GABAergic neurons, project to different hypothalamic areas (Jakab and Leranth, 1995). According to a recent study, the hippocamposeptal projection "is organized in such a way that different hippocampal regions map in an orderly way onto hypothalamic systems mediating the expression of different classes of goal-oriented behavior" (Risold and Swanson, 1996). The same authors demonstrated that the CA3 subfield projects selectively to the caudal part of the LS, which in turn projects to the lateral supramammillary nucleus. As shown in this study, the majority of supramammilloseptal aspartate/glutamatergic CR neurons are in this supramammillary subfield. Furthermore, this study found that supramammillary area CR efferents, in addition to being in other septal compartments, were seen in the aforementioned caudal part of the LS as well.

These new data, together with the observations of this study on the synaptic contacts between CR-containing supramammillary aspartate/glutamatergic neurons and medial septal area cholinergic neurons, allowed us to design a new hypothetical circuitry responsible for maintaining hippocampal theta rhythms (Fig. 6). (1) Supramammillary area aspartate/glutamatergic neurons convert the nonrhythmic flow of pulses from the reticular formation into theta rhythmic activity (Kocsis and Vertes, 1994), and (2) they drive the medial septal (cholinergic) pacemaker cells that (3) terminate on both hippocampal principal (Frotscher and Leranth, 1985, 1986) and nonprincipal neurons (Leranth and Frotscher, 1989); (4) in turn, hippocampal principal neurons terminate on lateral septal area GABAergic CB neurons (Jakab and Leranth, 1995) that project to the lateral supramammillary area (Risold and Swanson, 1996). The activity of this circuitry can be controlled by a GABAergic medial septum-LS projection (Leranth et al., 1992), as well as by aspartate/glutamatergic supramammillary fibers terminating on the lateral septal area CB neurons (recent study). Whether the latter connections are directly associated with the regulation of theta rhythm generation, however, or whether they influence only the hippocampal downstream signal flow, is not yet known. Furthermore, the possible supramammillary excitatory amino acid innervation of septohippocampal GABAergic neurons (Freund and Antal, 1988) should be elucidated.

In conclusion, this study demonstrated intrinsic and extrinsic CR systems in the septal complex. The former establishes symmetric synaptic contacts with lateral septal area CB neurons. A

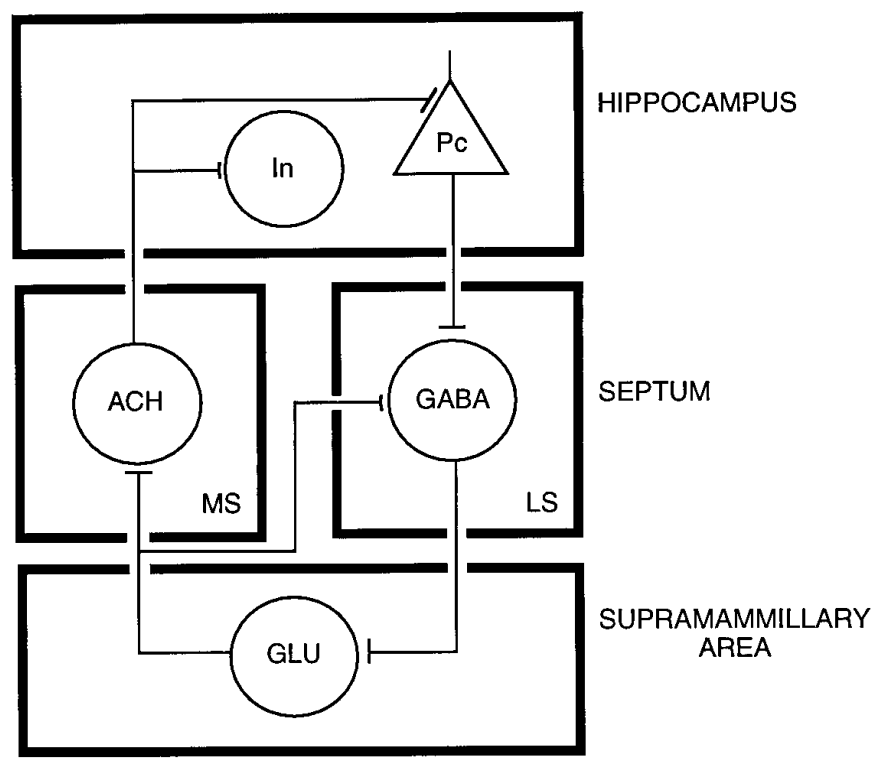

Figure 6. Schematic representation of the suggested connections between the hippocampal formation, medial $(M S)$ and lateral septum $(L S)$, and supramammillary area (based on recent observations and other published data). Hippocampal principal cells $(P c)$ terminate on lateral septal area projective neurons (including CB-containing GABAergic cells), which terminate on supramammillary area CR-containing cells, among them aspartate/glutamatergic $(G L U)$ CR neurons. These cells send excitatory stimuli to a population of medial septal area cholinergic $(\mathrm{ACH})$ cells and a large number of lateral septal area CB-containing GABAergic neurons $(G A B A)$. In turn, these medial septal area cholinergic neurons can control the activity of the hippocampus via their synapses on both hippocampal $P c$ and GABAergic interneurons (In).

population of the latter is an aspartate/glutamatergic CR system, which originates in the supramammillary area and forms asymmetric synapses with lateral septal area CB neurons and a population of medial septal area cholinergic cells. The connections of the latter may be essential in hippocampal immobility-related theta rhythm generation.

\section{REFERENCES}

Alonso A, Kohler C (1982) Evidence for separate projections of hippocampal pyramidal and non-pyramidal neurons to different parts of the septum in the rat brain. Neurosci Lett 31:209-214.

Alonso JR, Gaztelu JM, Buno Jr W, Garcia-Austt E (1987) Crosscorrelation analysis of septohippocampal neurons during theta-rhythm. Brain Res 413:135-146.

Apostol G, Creutzfeld OD (1974) Cross-correlation between the activity of septal units and hippocampal EEG during arousal. Brain Res 67:65-75.

Barbaresi P, Fabri M, Conti F, Manzoni T (1987) D- $\left[{ }^{3} \mathrm{H}\right]$ aspartate retrograde labelling of callosal and association neurons of somatosensory areas I and II of cats. J Comp Neurol 263:159-178.

Baughman RW, Gilbert CD (1981) Aspartate and glutamate as possible neurotransmitter in the visual cortex. J Neurosci 1:427-439.

Bland BH (1986) The physiology and pharmacology of hippocampal formation theta rhythms. Prog Brain Res 26:1-54.

Carnes KM, Fuller TA, Price JL (1990) Sources of presumptive glutamatergic/aspartatergic afferents to the magnocellular basal forebrain in the rat. J Comp Neurol 302:824-852.

Christie MJ, Summers RJ, Stephenson JA, Cook CJ, Beart PM (1987) Excitatory amino acid projections to the nucleus accumbens septi in the rat: a retrograde transport study utilizing $\mathrm{D}-\left[{ }^{3} \mathrm{H}\right]$ aspartate and $\left[{ }^{3} \mathrm{H}\right]$ GABA. Neuroscience 22:425-439.

Cuenod M, Streit P (1983) Neuronal tracing using retrograde migration of labeled transmitter-related compounds. In: Handbook of chemical neuroanatomy, Vol 1, Methods in chemical neuroanatomy (Bjorklund A, Hokfelt T, eds), pp 366-397. Amsterdam: Elsevier. 
DeFrance JF, Shimono T, Kitai ST (1971) Anatomical distribution of the hippocampal fibers afferent to the lateral septal nucleus. Brain Res 34:176-180.

DeFrance JF, Yoshihara H, Chronister RB (1976) Electrophysiological studies of the septal nuclei. I. The lateral septal nuclei. Exp Neurol 53:399-419.

Dememes D, Raymond J, Sans A (1984) Selective retrograde labeling of neurons of the cat vestibular ganglion with ${ }^{3} \mathrm{H}$-aspartate. Brain Res 304:188-191.

Eccles JC (1964) The physiology of synapses. Heidelberg: Springer.

Freund TF, Antal M (1988) GABA-containing neurons in the septum control inhibitory interneurons in the hippocampus. Nature 336:170-173.

Frotscher M, Leranth C (1985) Cholinergic innervation of the rat hippocampus as revealed by choline acetyltransferase immunocytochemistry: a combined light and electron microscopic study. J Comp Neurol 239:237-246.

Frotscher M, Leranth C (1986) The cholinergic innervation of the rat fascia dentata: identification of target structures on granule cells by combining choline acetyltransferase immunocytochemistry and Golgi impregnation. J Comp Neurol 43:58-70.

Fuller TA, Price JL (1988) Putative glutamatergic and/or aspartatergic cells in the main and accessory olfactory bulbs of the rat. J Comp Neurol 276:209-218.

Fuller TA, Russchen FT, Price JL (1987) Sources of presumptive glutamatergic/aspartatergic afferents to the rat ventral striatopallidal region. J Comp Neurol 258:317-338.

Gaztelu JM, Buno Jr W (1982) Septo-hippocampal relationships during EEG theta rhythm. Neurophysiology 54:375-387.

Gogolak G, Stumpf C, Petsche H, Sterc J (1968) The firing pattern of septal neurons and the form of the hippocampal theta wave. Brain Res 7:201-207.

Green JD, Arduini A (1954) Hippocampal electrical activity in arousal. J Neurophysiol 17:533-557.

Gulyas AI, Miettinen R, Jakobowitz DM, Freund TF (1992) Calretinin is present in nonpyramidal cells of the rat hippocampus. I. A new type of neuron specifically associated with the mossy fiber system. Neuroscience 48:1-27.

Jakab RL, Leranth C (1995) Septum. In: The rat nervous system (Paxinos G, ed), pp 405-442. New York: Academic.

Jung R, Kornmuller A (1938) Eine Methodik der Ableitung lokalisierter Potential-Schwankungen aus subkortikalen Hirngebieten. Arch Psychiatr Nervenkr 109:1-30.

Kirk IJ, McNaughton N (1991) Supramammillary cell firing and hippocampal rhythmical slow activity. NeuroReport 2:723-725.

Kiss J, Szeiffert G (1995) Topographic analysis of connections between the rat septal diagonal band complex and the supramammillary area. Fourth IBRO World Congress of Neuroscience, Rapid communications of Oxford Ltd., p 389.

Kisvarday ZF, Cowey A, Smith AD, Somogyi P (1989) Interlaminar and lateral excitatory amino acid concentrations in the striate cortex of monkey. J Neurosci 9:667-682.

Kocsis B, Vertes RP (1994) Characterization of neurons of the supramammillary nucleus and mammillary body that discharge rhythmically with the hippocampal theta rhythm in the rat. J Neurosci 14:7040-7052.

Kohler C, Chan-Palay V (1983) Distribution of gamma aminobutyric acid-containing neurons and terminals in the septal area: an immunohistochemical study using antibodies to glutamic acid decarboxylase in the rat brain. Anat Embryol 167:53-65.

Kosaka T, Nagatsu I, Wu J-Y, Hama K (1986) Use of high concentrations of glutaraldehyde for immunocytochemistry of transmittersynthesizing enzymes in the central nervous system. Neuroscience 18:975-990.

Lamour Y, Dutar P, Joberty A (1984) Septo-hippocampal and other medial septum-diagonal band neurons: electrophysiological and pharmacological properties. Brain Res 309:227-239.

Leranth C, Frotscher M (1989) The organization of the septal region in the rat brain: cholinergic-GABAergic interconnections and the termination of hippocampo-septal fibers. J Comp Neurol 289:304-314.

Leranth C, Nitsch R (1994) Morphological evidence that hypothalamic substance P-containing afferents are capable of filtering the signal flow in the monkey hippocampal formation. J Neurosci 14:4079-4086.

Leranth C, Deller T, Buzsaki G (1992) Intraseptal connections redefined: lack of lateral septum to medial septum path. Brain Res 583:1-11.
Luiten PGM, Kuipers F, Schuitmaker H (1982) Organization of diencephalic and brainstem projections to the lateral septum in the rat. Neurosci Lett 30:211-216.

Magloczky Z, Acsady L, Freund TF (1994) Principal cells are the postsynaptic targets of supramammillary afferents in the hippocampus of the rat. Hippocampus 4:322-334.

McLennan H, Miller JJ (1974) The hippocampal control of neuronal discharges in the septum of the rat. J Physiol (Lond) 237:607-624.

McLennan H, Miller JJ (1976) Frequency related inhibitory mechanism controlling rhythmical activity in the septal area. J Physiol (Lond) 254:827-841.

Matute C, Streit P (1985) Selective retrograde labeling with D- $\left[{ }^{3} \mathrm{H}\right]-$ aspartate in afferents to the mammalian superior colliculus. J Comp Neurol 241:34-49.

Nayar R, Sirett NE, Hubbard JI (1987) Neuron responses to substance P and enkephalin in the rat dorso-lateral septum in vitro. Brain Res Bull 19:507-509.

Nitsch R, Leranth C (1993) Calretinin immunoreactivity in the monkey hippocampal formation. II: Intrinsic GABAergic and hypothalamic non-GABAergic systems. An experimental tracing and coexistence study. Neuroscience 55:797-812.

Nitsch R, Leranth C (1994) Sprouting of intrinsic substance $\mathrm{P}$-immunoreactive fibers in the monkey dentate gyrus following denervation from its substance P-containing hypothalamic afferents. Exp Brain Res 100:522-526.

Nitsch R, Leranth C (1996) GABAergic neurons in the rat dentate gyrus are innervated by subcortical calretinin-containing afferents. J Comp Neurol 364:425-438.

Oddie SD, Bland BH, Colom LV, Vertes RP (1994) The midline posterior hypothalamic region comprises a critical part of ascending brainstem hippocampal synchronizing pathway. Hippocampus 4:454-473.

Oliver DL, Potshner SJ, Jones DR, Morest DK (1983) Selective labeling of spiral ganglion and granule cells with D-aspartate in the auditory system of cat and guinea pig. J Neurosci 3:455-472.

Onteniente B, Tago H, Kimura H, Maeda T (1986) Distribution of gamma aminobutyric acid-immunoreactive neurons in the septal area of the rat brain. J Comp Neurol 248:422-430.

Panula P, Revuelta AV, Cheney DL, Wu J-Y, Costa E (1984) An immunohistochemical study in the location of GABAergic neurons in rat septum. J Comp Neurol 222:69-80.

Petsche H, Stumpf G, Gogolak G (1962) The significance of the rabbit septum as a relay station between the midbrain and the hippocampus. I. The control of hippocampus arousal activity by the septum cells. Electroencephalogr Clin Neurophysiol 14:202-211.

Risold PY, Swanson LW (1996) Structural evidence for functional domains in the rat hippocampus. Science 277:1484-1486.

Rogers JH (1987) Calretinin: a gene for a novel calcium-binding protein expressed principally in neurons. J Cell Biol 105:1343-1353.

Rustioni A, Cuenod M (1982) Selective retrograde transport of $\mathrm{D}$-aspartate in spinal interneurons and cortical neurons of rats. Brain Res 236:143-155.

Saper CB (1985) Organization of cerebral cortical afferent systems in the rat. II. Hypothalamocortical projections. J Comp Neurol 237:21-46.

Shinoda K, Tohyama M, Shiotani Y (1987) Hippocampofugal gammaaminobutyric acid (GABA)-containing neuron system in the rat: a study using a double-labeling method that combines retrograde tracing and immunohistochemistry. Brain Res 409:181-186.

Staiger JF, Nurnberger F (1991) The efferent connections of the lateral septal nucleus in the guinea pig: intrinsic connectivity of the septum and projections to other telencephalic areas. Cell Tissue Res 264:415-426.

Storm-Mathisen J, Leknes AK, Bore AT, Vaaland JL, Edminson P, Haug FMS, Ottersen OP (1983) First visualization of glutamate and GABA in neurons by immunocytochemistry. Nature 301:517-520.

Streit P (1980) Selective retrograde labeling indicating the transmitter of neuronal pathways. J Comp Neurol 191:429-463.

Swanson LW, Cowan WM (1979) The connection of the septal region in the rat. J Comp Neurol 186:621-656.

Szeidemann Z, Jakab RL, Shanabrough M, Leranth C (1995a) Extrinsic and intrinsic substance $\mathrm{P}$ innervation of the rat lateral septal area calbindin cells. Neuroscience 69:1205-1221.

Szeidemann Z, Shanabrough M, Leranth C (1995b) Hypothalamic Leuenkephalin immunoreactive fibers terminate on calbindin containing 
somatospiny cells in the lateral septal area of the rat. J Comp Neurol 358:573-583.

Toth K, Freund TF (1992) Calbindin D28k-containing nonpyramidal cells in the rat hippocampus: their immunoreactivity for GABA and projection to the medial septum. Neuroscience 49:793-805.

Twery MJ, Phelan KD, Gallagher JP (1990) Bursting and non-bursting neurons in the rat dorsolateral septal nucleus. Soc Neurosci Abstr 16:58.

Varoqueaux F, Leranth C (1996) Hypothalamo-septal enkephalinergic fibers terminate on AMPA receptor-containing neurons in the rat lateral septal area. Synapse, in press.

Vertes RP (1988) Brainstem afferents to the basal forebrain in the rat. Neuroscience 24:907-935.
Vertes RP (1992) PHA-L analysis of projections from the supramammillary nucleus in the rat. J Comp Neurol 326:595-622.

Vinogradova OS, Brazhnik ES, Karanov AM, Zhadina SD (1980) Neuronal activity of the septum following various types of deafferentation. Brain Res 187:553-368.

Witter MP, Daelmans HEM, Jorritsma-Byham B, Staiger JF, Wouterlood FG (1992) Restricted origin and distribution of projections from the lateral to medial septal complex in rat and guinea pig. Neurosci Lett 148:164-168.

Zamir N, Palkovits M, Weber E, Mezey E, Brownstein MJ (1984) A dynorphinergic pathway of Leu-enkephalin production in rat substantia nigra. Nature 307:643-645. 